\title{
A Role for Immersive Visualization Experiences in Teaching Archaeology
}

\author{
KEVIN GARSTKI, University at Buffalo, NY, USA \\ CHRIS LARKEE, Marquette University, WI, USA \\ JOHN LADISA, Marquette University, WI, USA
}

\begin{abstract}
As archaeologists continue to utilize digital 3D visualization technologies, instruction can also benefit from purpose-driven uses of these data. This paper outlines a pilot project that used previously captured 3D data in a large-scale immersive environment to supplement the instruction of basic archaeological concepts to an undergraduate introductory anthropology class. The flexibility of the platform allowed excavation trenches to be investigated in three-dimensions, enhancing the understanding of excavation methods and providing additional insight in the choices of the excavators. Additionally, virtual investigation of the artifacts provided a way for students to interact with objects on the other side of the world in a more complete way. Instructor-led immersive virtual experiences have significant potential to widen the interest in archaeology and enhance the instruction of archaeological concepts. They allow students to interact with the content, guided by an expert, and in the presence of each other. While the facilities are not available at every university at the current time, the cost effectiveness and ability to deliver these experiences via head-mounted displays represents an exciting potential extension for complementary self-paced, yet guided, exploration.
\end{abstract}

\section{Key words:}

Pedagogy; Immersive visualization; Photogrammetry; Structured light scanning; Virtual Reality

SDH Reference: Kevin Garstki et. al. 2019. A Role for Immersive Visualization Experiences in Teaching Archaeology. SDH, 3, 1, 46-59.

DOI : $10.14434 /$ sdh.v3i1.25145

\section{INTRODUCTION}

The use of digital technologies for the creation of digital 3D representations of artifacts and to document archaeological excavation has increased at a rapid rate in recent years. As archaeologists are beginning to move past the "trial phase" of data capture in the field, many are questioning the utility of these new 3D data and their impact on the creation of archaeological knowledge [e.g. Howland 2018; Dell'Unto 2018; Roosevelt et al. 2015; Garstki 2018]. The question that often remains is: now that we have this data, what do we do with these 3D models? How can they be disseminated for use by a wider audience and in a format true to their intended context and impressive form? With

Author's address: Kevin Garstki, Institute for European and Mediterranean Archaeology, University at Buffalo, SUNY, 380 MFAC Ellicott Complex, Buffalo, NY 14261, USA; email: kjgarstk@buffalo.edu; Chris Larkee and John LaDisa, MARVL: the MARquette Visualization Lab, Opus College of Engineering, Marquette University, 1637 W. Wisconsin Ave, Milwaukee, WI 53201, USA; email: christopher.larkee@marquette.edu; john.ladisa@marquette.edu.

(C) [2019] by the author; licensee Studies in Digital Heritage, IU, Bloomington (IN), USA. This article is an open access article distributed under the terms and conditions of the Creative Commons Attribution License (CC BY-NC). 
this increased access to digital 3D data of extant objects and sites, we believe their application in educational contexts has been under-utilized. There is great potential for using these data to enhance the teaching of archaeological methods, in addition to engaging students through the visuals. As we've found, 3D models of excavation trenches, or artifacts can act as important supplements to help express complex archaeological concepts that may only have been previously possible in an excavation or museum.

Previous projects have outlined the utility of using 3D virtual environments to express archaeological concepts and excavation techniques through displays such as the Powerwall and Cave systems [e.g. Galeazzi et al. 2010; Levy et al. 2010; Forte 2014; Knabb et al. 2014; Galeazzi and Di Giuseppantonio Di Franco 2017]. The 3D Virtual Dig (3VD) developed at the University of California, Merced was a 3D application aimed at teaching excavation techniques in an introductory archaeology course [Di Giuseppantonio Di Franco et al. 2012]. This application utilized previously produced 3D models at the site of Çatalhöyük, Turkey to teach introductory students basic methods of archaeological excavation and stratigraphy. Through a guided activity comparing the 3D application with a 2D exercise focused on the same stratigraphic contexts, the researchers found that the use of this virtual excavation application aided students in the retention of information and later use of that information on a formal assessment [Di Giuseppantonio Di Franco et al. 2012]. As successful as this application was, the authors noted that there were still drawbacks to the platform. The benefits of transferring this 3D data into an immersive VR system was also outlined by Forte [2014]. 3D data in the form of stratigraphic models from Çatalhöyük were also utilized in the Duke Immersive Visualization Environment's (DiVE) CAVE system that allowed people to interact with the models in a 3 x 3 x 3m room [Forte 2014: 19-23]. While an extremely innovative use of the technology, Forte notes that the facilities only allow small groups to experience the virtual environment, which means the application is unfortunately ill-suited to instructional lessons to larger classes.

Prior to the 2017-2018 school year, we began working on a pilot project aimed at determining the efficacy of digital 3D artifact and excavation models for teaching introductory archaeology concepts. These models were specifically designed to be experienced within the MARquette Visualization Lab (MARVL). MARVL's state-of-the-art, 1,700 sq ft facility includes a large-scale immersive environment (i.e. CAVE)[Cruz-Neira 1992] with stereoscopic viewing for improved depth cues, surround sound, and motion tracking. Importantly MARVL was developed with collaboration and educational objectives in mind. It has space for 30 people to view content that has been filmed, reconstructed or created computationally (Fig. 1). The virtual scene used for this introductory class was a minimalist geometric space, reminiscent of a sculpture garden: a large, 120 foot circle of fine gravel, surrounded by a border of smooth concrete. The artifacts were collected into three groups, gathered in different quadrants of the circle. Smooth brown and black gradients were used for the skybox beyond the dias. The user's point of view was given the ability to float up and down freely, and so the artifacts were placed at eye level, floating above the ground without support, along with their captions. Most artifacts were scaled to approximately four times their original size, to make it easier to examine their detail. 


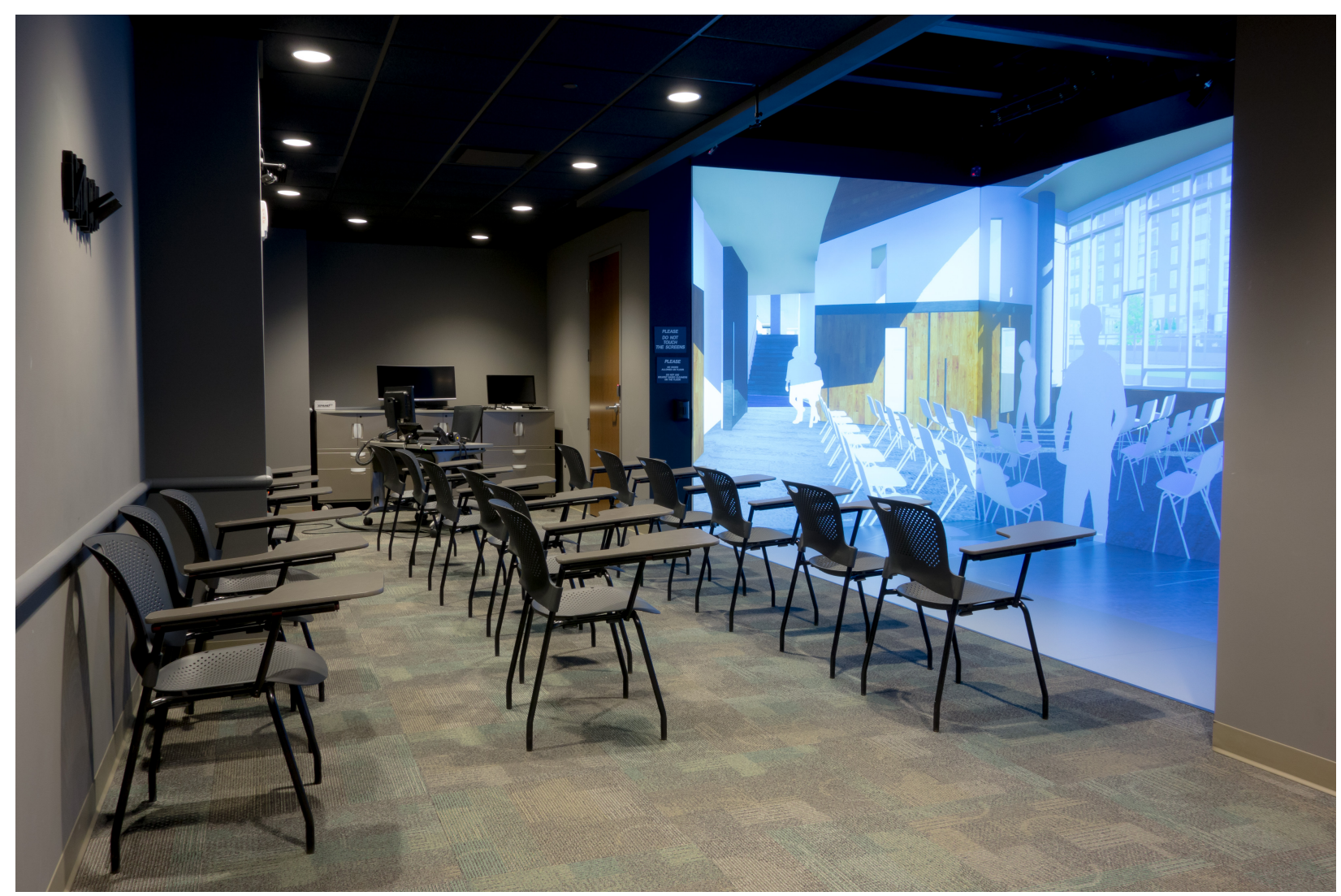

Figure 1. Layout of MARVL's large-scale immersive environment

This scene was used as a supplement to the course material covered as part of Marquette University's Anthropology 1001: Introductory Anthropology. The primary goals of this project were to create a virtual environment that was coupled with faculty instruction aimed at meeting the learning goals of the class. Since a goal of this course was to develop broad critical thinking skills in the social sciences, it was important to successfully convey to the students the processes by which archaeologists go from excavation to making conclusions about past peoples. Through the class periods students were able to virtually move down through an excavation trench as if they were part of the excavating process, accompanied by real-time description and explanation of the professor, who in this case was also the archaeologist. The ability to simultaneously visualize the excavations in both horizontal and vertical planes allowed the students to develop greater spatial understanding of the site, more so than looking at a 2D plan map or profile drawing. They were also able to closely examine the three dimensional nature of artifacts to learn about distinct evidence for production, as well as investigating standing architecture to engage with the ways archaeologists interpret ancient structures.. This project developed a virtual experience that is driven by course instruction within a new avenue to engage with course concepts. The project demonstrated that an integration of new media in archaeological instruction can appeal to a wider number of students without altering the core mission of the course. 


\section{THE VIRTUAL REALITY (VR) PLATFORM AND DATA}

This pilot project benefited greatly from collaboration across university departments and from the resources available at Marquette University. Both the data and the infrastructure to use them were already in place at the onset of this project, allowing relatively limited front end data creation.

\subsection{MARVL}

MARVL content, in this case an excavation site, is driven by hardware consisting of six image generators (i.e. computers). There is a primary image generator (Z820 E5-2670 workstation with 1TB HDD and 32GB RAM; Hewlett-Packard, Palo Alto, California) containing a single graphics card (Quadro K5000; Nvidia Corp.; Santa Clara, California), which communicates control to five additional Z820 image generators via a local Ethernet network isolated from the campus network. Image generators beyond the primary are configured with two Nvidia Quadro M4000 graphics cards and a single Quadro Sync Interface Board. The graphics cards collectively provide 10 output channels, one for each of MARVL's ten projectors (Mirage WU7K-M projectors with Twist; Christie Digital, Cypress, California). Images rendered by the 10 projectors are warped and blended to cover multiple display surfaces including an extra wide front wall (4 projectors) as well as the floor, and two side walls ( 2 projectors each). The result is stereoscopic projection and enhanced depth cues over a viewable dimension of 18'6" (front) x 9'3" (height) x 9'3" (depth). Resolution is 4K on the front wall, with a total system resolution of 15.7 megapixels. All image generators are running Microsoft Windows 7 Professional 64-bit. Interaction within the virtual environment is afforded by a tracking system consisting of 6 ARTTRACK2 cameras and a FlyStick2 wireless interaction device (Advanced Realtime Tracking; Weilheim, Germany).

\subsection{The Data}

The scene used for the classes consisted of six photogrammetric excavation models and three 3D artifact representations. The data used for this project came from previous projects that were centered on the creation of 3D archaeological representations for research use [Garstki et al. 2018; Counts et al. 2016; Counts et al. forthcoming]. One significant focus of the class was a $2 \times 1 \mathrm{~m}$ excavation trench from the Guard site (12D29), an early Fort Ancient village (ca. 1000 - 1300 C.E.) found in southeast Indiana [Cook et al. 2015]. A series of models were created using "Structure from Motion" (SfM) at various depths of the excavation trench. The models were created during the 2016 field season as part of a project to incorporate computational photogrammetry into the excavation methods in the Midwest United States and identify its appropriateness for existing archaeological workflows [Garstki et al. 2018]. During this season, one trench placed over Anomaly 167 was chosen to document at multiple stages through the excavation, highlighting the choices of the excavators through SfM. Five models were created at different intervals through the excavation of the trench, from $40-120 \mathrm{~cm}$ below the surface (cmbs) (Fig. 2). 
1:50 K. Garstki, et al.
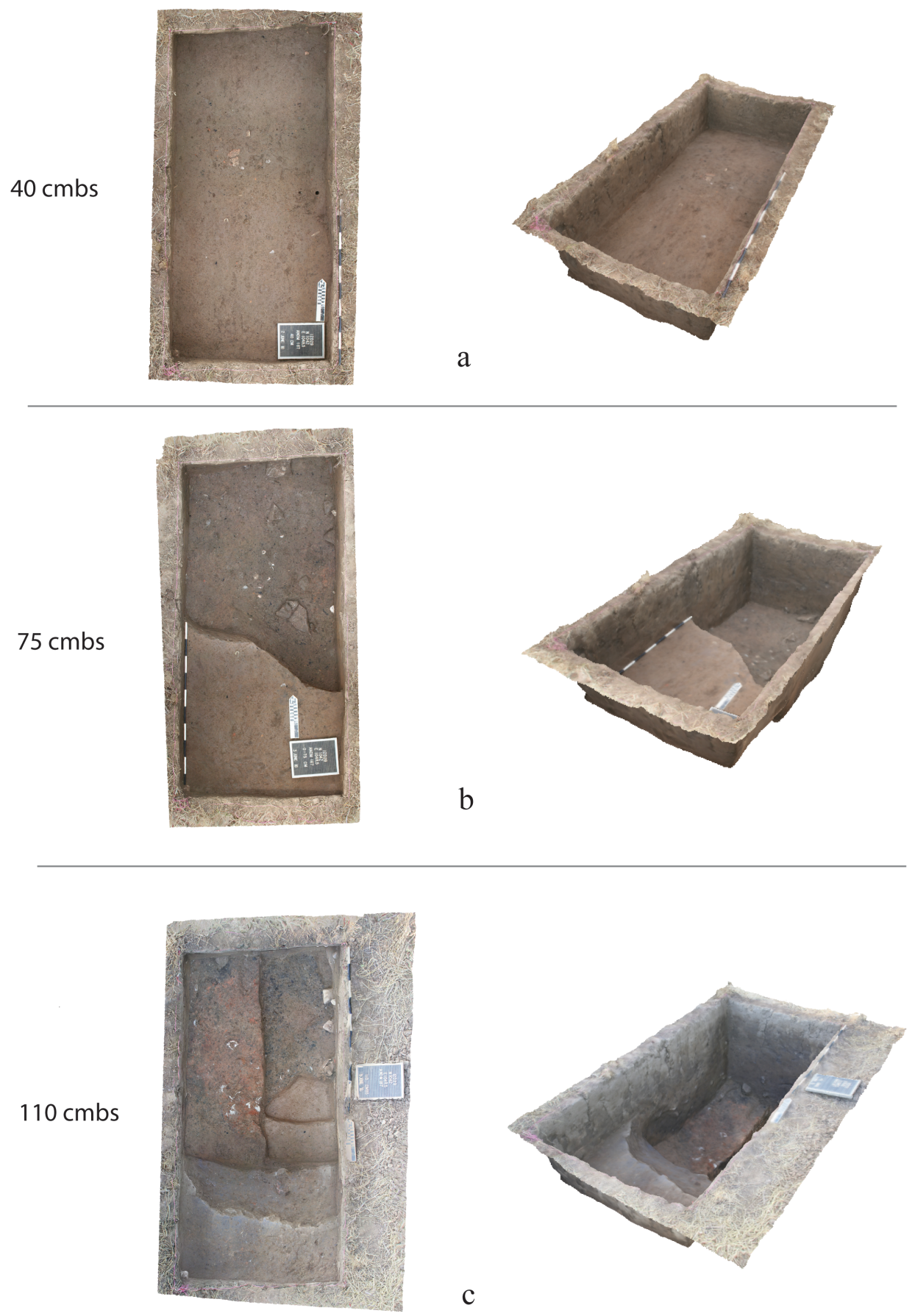

Figure 2. Anomaly 167 from the Guard Site at three of the five stages of excavation and documentation: a) trench at $40 \mathrm{~cm}$ below surface; b) trench at $75 \mathrm{~cm}$ below surface; c) trench at $110 \mathrm{~cm}$ below surface 
The 3D artifact representations utilized in the scene came from the Athienou Archaeological Project (AAP). AAP has been researching long-term culture change occurring at the site of AthienouMalloura and in the surrounding region since 1990 through archaeological survey and excavation [Toumazou et al. 2011, 2015]. For more than a decade, the focus of AAP has been on a large rural sanctuary, in use from the 8th century BCE - 4th century CE. The project began work in 2014 to document the terracotta and limestone statuary from the sanctuary of Athienou-Malloura using structured light scanning [Counts et al. 2016]. The three artifacts used in this teaching scene included a terracotta mask, a limestone head, and a limestone chariot created using an HDI Advance R1X structured light scanner from GoMeasure3D. An additional set of models were used in the scene that depict a portion of the sanctuary at Athienou-Malloura, created by the first author using computational photogrammetry following the 2017 field season. Each one of these 3D models were chosen to use in this pilot project to demonstrate one or more concepts of archaeological method and process to students. However, it should also be noted that these data were not created with the intention of using them in this platform or necessarily for instructional purposes. As will be discussed below, there may be drawbacks to this type of ad hoc use of digital visual data for instruction.

\subsection{Development of the scene}

The models were provided to MARVL in the Collada/DAE format, which was chosen for its interoperability between the scanning software and Blender (Blender Foundation; Amsterdam, NL). Although the final scene would be built in the Unity game engine (Unity Technologies, San Francisco, $\mathrm{CA})$, Blender was necessary to provide some additional mesh processing to prepare the models for VR. We wanted the user to be able to rotate and manipulate the models within the immersive VR environment, so it was important that all the models have a consistent scale and default orientation, and that their origin is in a sensible position near the object's center of gravity. In some cases, it was beneficial to use a 'decimate' filter to reduce the object's vertex count. The scanned models were intentionally extremely high detail and dense in order to maintain the fidelity to the original artifact or excavation, but for display purposes, we were able to easily reduce the vertex count from 500k to $64 \mathrm{k}$ without introducing any artifacts or loss in details. We retained the full resolution of the original scanned textures, which also preserved the visual quality.

After the models were prepared, it was a straightforward procedure to import the models into Unity using a typical workflow. We created an environment to house the models, positioned the models in the scene, lit them, and added text captions (Fig. 3). MiddleVR (Le Kremlin-Bicêtre, France) was added to the Unity project, providing support for displaying the virtual scene in the MARVL large-scale

immersive environment, as well as providing a user movement system via the ARTTRACK Flysticks and tracking system. 


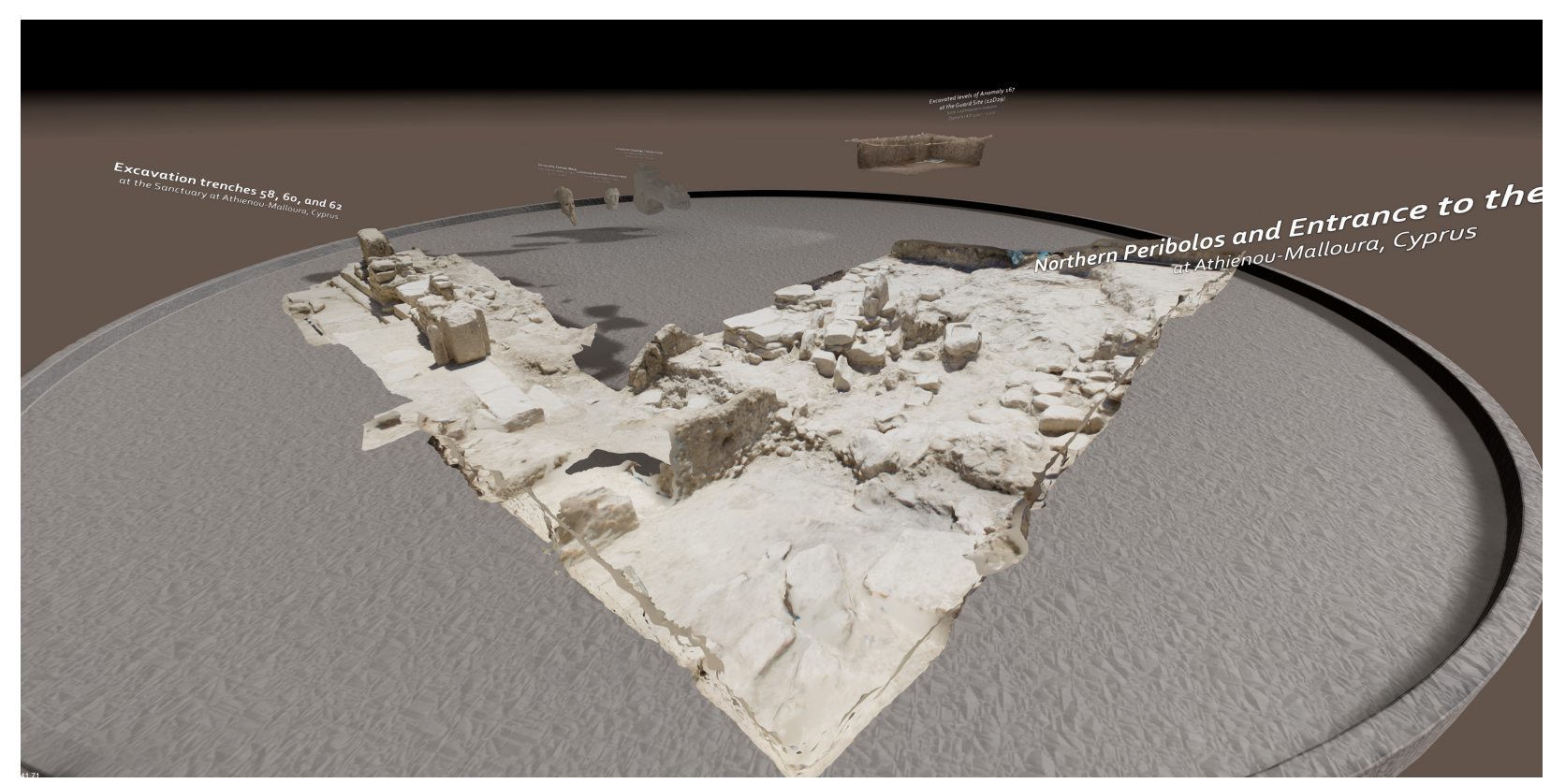

Figure 3. The virtual scene used in the class, visualized through Unity.

Although both scanning techniques capture colored texture, each method handles lighting in a slightly different way. Structured light scanning, as used on the artifacts, are captured in a state of neutral lighting, free from ambient lighting and self-shadowing, allowing them to be virtually re-lit with virtual lights in a fashion that is artistically configurable and consistent with their new surroundings. Photogrammetry, as used on the site scans, captures the natural lighting of the captured environment, baking the diffuse lighting into its texture. In order to present the captured lighting as intended, a custom shader was written for Unity, modifying the highly performant and simple 'unlit' shader to utilize vertex colors.

\section{CLASSROOM EXPERIENCE}

Students from Anthropology 1001: Introductory Anthropology were brought to the large-scale immersive environment within MARVL during the fall semester of 2017 and spring semester of 2018 to experience complementary lessons on archaeological methods. ANTH 1001 is intended to introduce students to the different ways anthropologists study humans and provide them with a holistic view of anthropological research. As such, limited time is allocated to very specific instruction on different anthropological methodologies, including archaeological excavation and materials analysis. The aim in using the large-scale immersive visualization system was to integrate and supplement the existing lecture structure, and not to simply provide an aesthetically pleasing visual for students to enjoy. In the weeks prior to the class held at MARVL, the professor (Garstki) introduced basic methodologies of archaeological excavation and material analysis through didactic lectures. The concepts addressed in lecture helped to foster an understanding of the tools archaeologists use to make statements about past peoples based on excavation data. Concepts 
included stratigraphy, excavation methods, and the ways archaeologists can use material culture to provide insight on the people who made and used them. As this course is not an introduction to solely archaeology, it was most important to make clear how archaeologists do their research, which in turn helps to develop the skills to critically assess arguments and conclusions made in the social sciences and humanities more broadly. Since MARVL's large-scale immersive environment can comfortably accommodate 30 students, as the class of 60 students was split into different groups to attend during different class periods. While an ideal scenario would allow each student to navigate their own way through the scene with the controls, the size of the class and the time limitation of the class period meant only the instructor controlled the scene.

The lesson began by contextualizing each archaeological site that was used in the scene; this included a short introduction to both the Fort Ancient village site and the sanctuary site of AthienouMalloura. The excavation strategy at the site of Guard, in which trenches were placed to test anomalies identified on previous magnetic gradiometry data [Cook et al. 2015; Garstki et al. 2018], was described and demonstrated to the students through 2D images and maps within MARVL. This was followed by the presentation of the scene to the students immersively using the full stereoscopic (i.e. 3D) projection system within MARVL's large-scale immersive environment, beginning with the Guard excavation trench. The first level of the Anomaly 167 trench began $40 \mathrm{cmbs}$ and showed the first identification of cultural material below the A horizon, demonstrated by the presence of darker soil and an artifact concentration. Students were shown these indicators of archaeological features in the model and it was explained how such indicators are used by archaeologists to understand the site they are excavating and what it tells us about the processes of use and deposition at the site. The feature that was identified in this trench was a pit that continued into the western, northern, and eastern walls of the trench. The next model (at $75 \mathrm{cmbs}$ ) illustrated the excavators' decision to remove only the cultural deposits, following the southern boundary of the feature (Fig. 4). Once again, the changes in soil coloration and different concentrations of artifacts were highlighted for the students. This level also illustrated an important concept in archaeological excavation: the need to reevaluate excavation strategies as the excavation proceeds. Due the diffuse boundary of the feature, it was decided to extend the excavation south to ensure full mitigation of the feature [Garstki et al. 2018: 142]. The ability to show the full context of the excavation trench, which includes the horizontal excavation surface as well as the profile stratigraphy, allows the students to better grasp the threedimensional space that was excavated and interpreted by the archaeologist. The models for this trench are followed at additional depths, illustrating different concentrations of artifacts, large stones, carbonized material, and eventually a discrete layer of ash and carbonized floral materials on the feature floor. This layer was bisected, further demonstrating to the students the excavators' choice of strategy for extracting as much data from the feature as possible. 


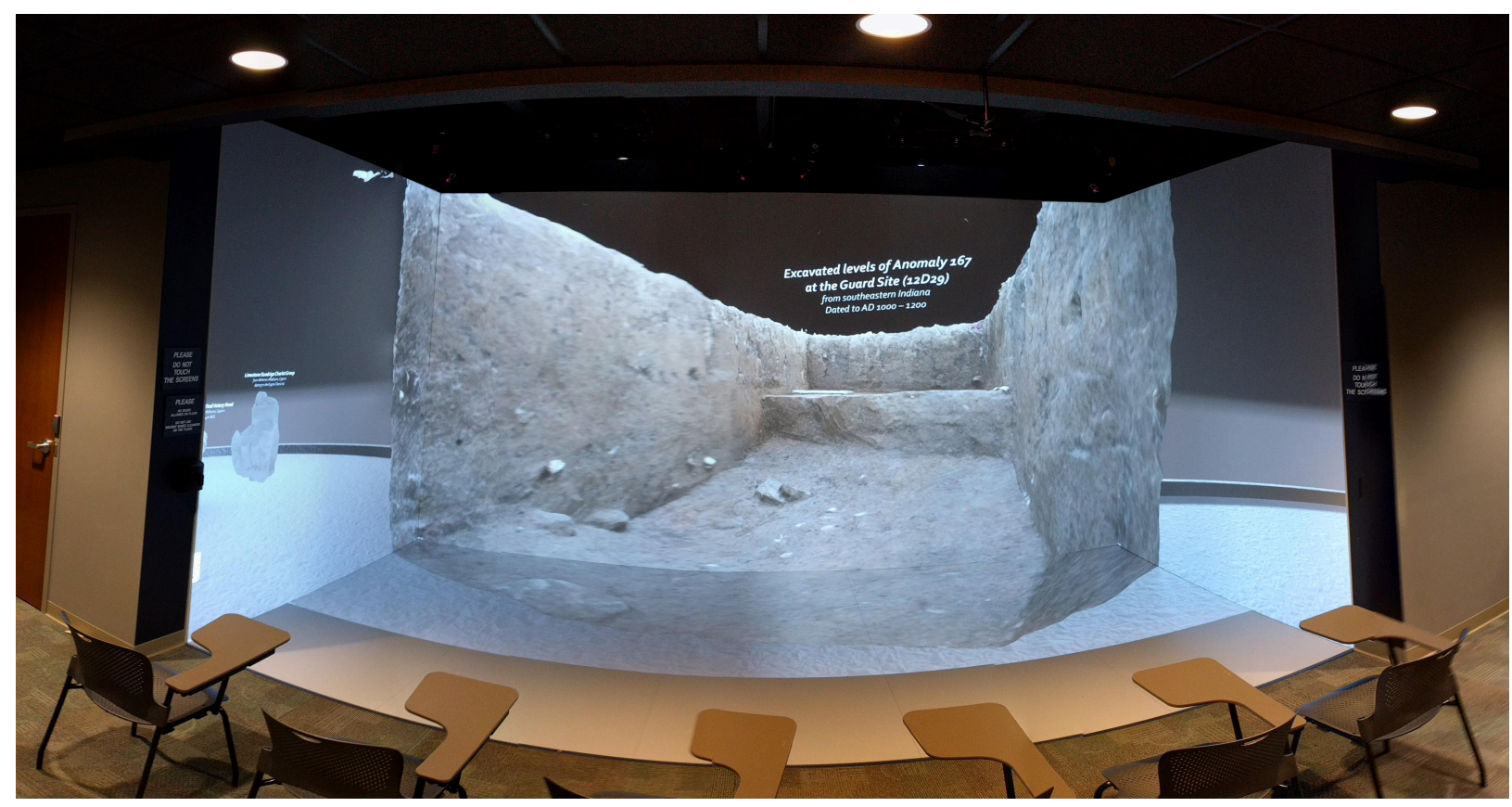

Figure 4. The Guard Site excavation trench model visualized in MARVL's large-scale immersive environment.

The next aspect of the scene used in the class was the photogrammetric model of a portion of the excavations at the sanctuary of Athienou-Malloura (Fig. 5).

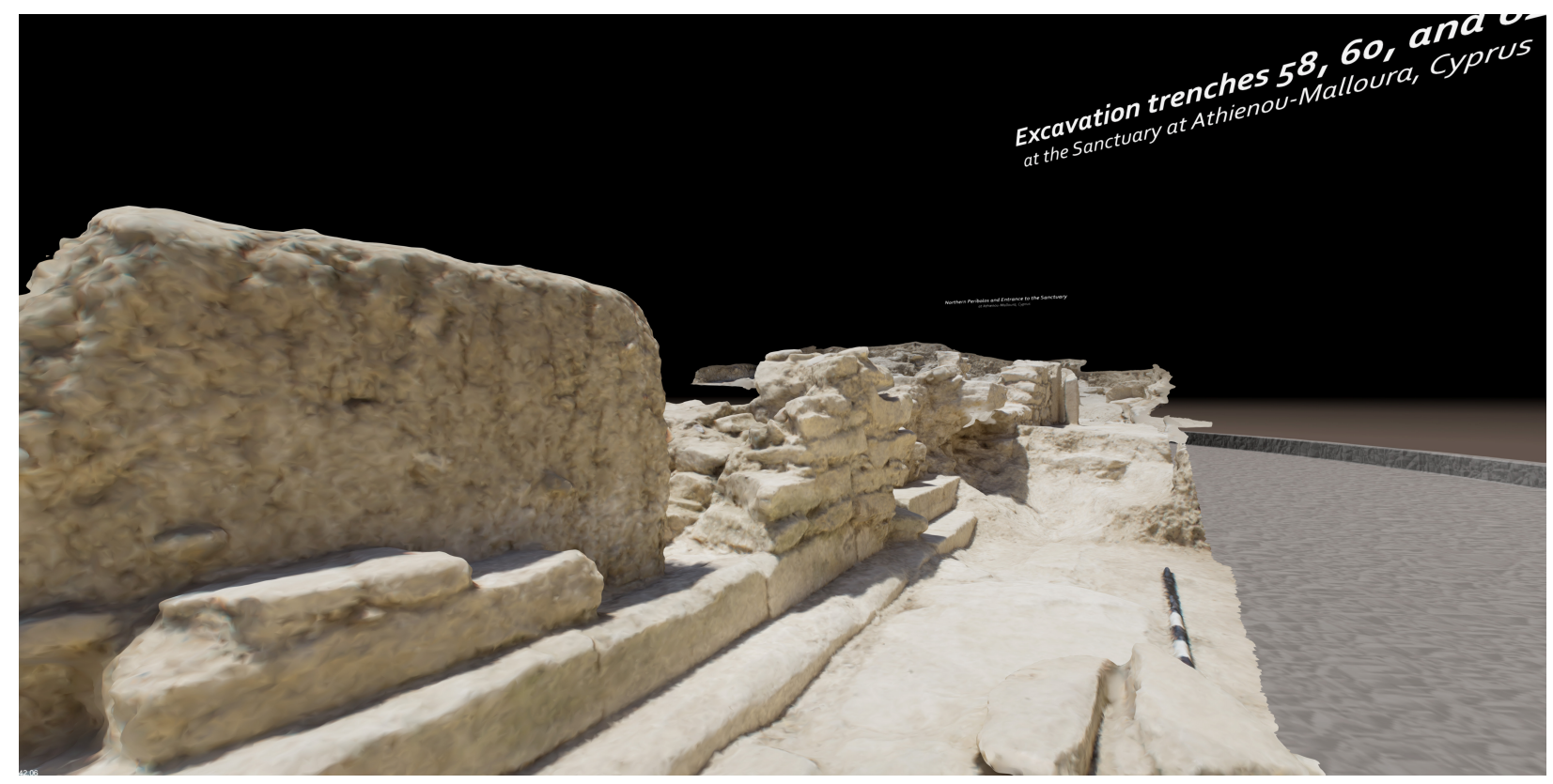

Figure 5. A 3D model of the northern portion of the sanctuary at Athienou-Malloura, visualized through Unity. 
One section of the model discussed in class emphasized how archaeologists utilize architectural features uncovered during an excavation to reconstruct the use of a site. This part of the model showed what has been interpreted as the entrance to the sanctuary, with a large re-used ashlar block standing as a door jamb and at its base a threshold stone for the entryway into the sanctuary [Toumazou et al. 2015: 210-211]. The students were able to view it as if we were in the field, seeing the architecture from all angles and helping them fully understand the features. This demonstrated to the students that since archaeologists are often relying on fragments of structures, we must utilize the entire context of the site to interpret what is being uncovered. Furthermore, this model also established for the students a persistent problem for many archaeological endeavors: looting. The threshold stone was broken by modern looting, an issue that has been contended with through the course of excavations here [Counts 1998: 57-58; Toumazou et al. 2015: 211; Toumazou and Counts 2011: $75]$. In this way, the class was able to address how investigations into the past by archaeologists can often conflict with the way people in recent history have interacted with a site or a region's archaeological past.

The final piece of the virtual scene was a very small collection of 3D artifact models recovered from the excavations at Athienou-Malloura. These models of votive offerings were used in a discussion of how archaeologists utilize different methods of artifact analysis to infer certain things about the past people who produced and used these artifacts. Interacting with 3D representations of these artifacts allowed the students to engage with the ways people were experiencing the sanctuary site and participating in religious practices. Additionally, the high resolution of these models and the ability to fully rotate and manipulate the artifacts provided an avenue to discuss production; for example, a fragmentary limestone quadriga visualized in the scene shows clear chisel marks on the bottom of the piece (Fig. 6) [Counts et al. forthcoming; Toumazou et al. 2015: 214].
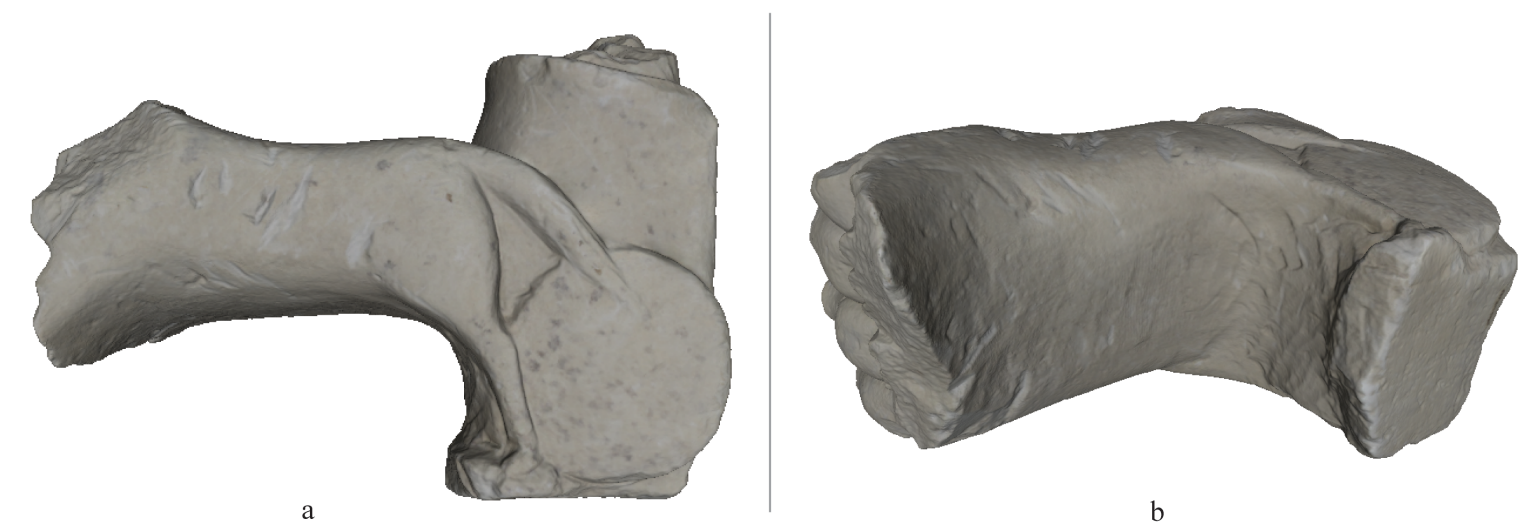

Figure 6. A 3D model of the limestone quadriga (AAP-AM-4360) used in the teaching scene: a) profile view of model; b) chisel marks visible on the underside of the artifact.

In addition to listening to the lecture and participating in discussion on the material visualized in the VR scene, students also answered written questions that highlighted different aspects of the lecture. These assessments included a question asking the students to explain the reasoning for different excavation decisions and to describe the other human processes affecting the preservation 
of architectural remains in an archaeological context. These class meetings were therefore meant to integrate many different learning strategies into the teaching of basic methods of archaeological research.

\section{BROADER IMPLICATIONS IN PEDAGOGY AND FUTURE DIRECTIONS}

The use of virtual archaeological sites and materials in research and education was realized early in the development of computer visualizations [e.g. Reilly 1992], and with the rise of virtual archaeological reproductions archaeologists also saw their potential for instruction [Clark et al. 2002; Sanders 1997; Terras 1999]. The visual nature of archaeological data lends itself well to using different computer platforms to teach archaeological concepts. Interactive applications such as Excavating Occaneechi Town: Archaeology of an Eighteenth-Century Indian Village in North Carolina [Davis et al. 1998], Virtual Dig: A simulated archaeological excavation of a Middle Paleolithic site in France [Dibble et al. 2000], and Adventures in Fugawiland: A Computer Simulation in Archaeology[Price and Gebauer 1997] are excellent examples of the ways in which computer technologies, including site and artifact representations, can aid in archaeological instruction in the classroom. As digital technologies developed, and the equipment capable of creating photo-realistic representations of archaeological sites and artifacts began to be used by archaeologists, a new avenue of instructional tools have also become available in the form of immersive virtual reality of excavations. A number of projects have since utilized these tools in an effort to extract the pedagogical potential of archaeological 3D models (Galeazzi et al. 2010; Levy et al. 2010; Forte 2014; Knabb et al. 2014; Galeazzi and Di Giuseppantonio Di Franco 2017).

We see immense benefit to the facilities within MARVL's large-scale immersive environment for integrating faculty instruction and virtual content. In contrast to having individual students interact with the material through a personal VR system like an Oculus Rift, this classroom allows many students to interact with the content, an expert who is walking them through what they are seeing, and each other. We feel these technologies can be truly integrated into the course structure by coupling the visuals with the course content and instruction. There was also a great benefit to having photorealistic models in this educational scene; the differences in soil coloration are a huge factor in determining stratigraphic changes and influencing archaeological process, especially in the Guard site trench. However, for future iterations of this project, a systematic questionnaire will need to be used to gauge the students' comprehension of the material versus more traditional forms of teaching.

As this was a pilot project to identify the educational benefits of utilizing these technologies in this introductory course, the models were not created with the intention of being visualized and used in this course. In the future, the use of 3D archaeological visualizations of all scales for instruction could be integrated into the data capture strategy of a larger project, excavation or artifact scanning. Of course, the financial limitations dictate that the sole goal of a 3D data capture project often cannot be for visualizing in an introductory course. However, this application should be considered when archaeologists have formed the appropriate collaborations across disciplines and have access to equipment or facilities capable of making use of visualizations in an educational context. In this way, future instructional VR scenes can be more geared to the lesson plan or concepts for a specific class. More detailed and expansive excavation models may be used to illustrate even more concepts in an

Studies in Digital Heritage, Vol. 3, No. 1, Publication date: June 2019 
introductory archaeology course, or additional artifact types can be used to facilitate specific upperlevel materials analyses courses (see recent work at Stanford University for an example [Engel 2017]).

\section{CONCLUSIONS}

The major drawback to this type of instructional program is the movement away from the haptic experience that permeates archaeological process. This classroom experience does not allow students to feel the texture or weight of an artifact or feel how the soil consistency changes when a trowel scrapes from cultural feature to sterile soil. Although haptic feedback has been incorporated into immersive environments previously, it was not employed for the current exercise. Di Giuseppantonio Di Franco et al. [2016] have rightly reinforced the importance of tactile experience in interacting with archaeological material. Following this, we are not suggesting that all archaeological instruction should now be conducted in a virtual environment, but that it could be used as a supplement to introduce basic concepts, and for higher-level training when access to materials or sites is limited.

A critique may be leveled that the visual appeal of these applications of archaeological data is merely masking an investment of time, energy, and money at the point of data capture that could be better spent elsewhere. And indeed, this may be the case in some instances. However, there is also a rise in purpose-driven digital methods in archaeology that are continuing to highlight the applicability of these technologies at various segments of archaeological work, whether in documentation, dissemination, or public outreach. The applicability of this pilot study across institutions will of course be dictated by the available facilities, and as in any instance of pedagogical planning, the techniques and technologies used should complement the learning goals rather than dictate them. Although many institutions may not yet have the facilities to conduct this type of classwork, these technologies will only become more and more common.

At this point we should not avoid the reality that the novelty of and excitement about these technologies can bring attention to archaeology. The benefit of utilizing various virtual technologies, as well as augmented reality, for bridging a gap between archaeologists and the public has been well argued [Ellenberger 2017]. We should not run from this excitement in favor of tradition, as it is another way to draw students in and provide entry points to archaeology. Presenting academically rigorous content through different media and platforms allows a complementary way for students to engage with archaeology and anthropology, especially for those who may not be immediately drawn to the class content. With an inherently visual and material discipline, the utility of immersive virtual reality in the absence of in-person experience is invaluable.

\section{ACKNOWLEDGEMENTS}

We would like to thank Michael Toumazou, Derek Counts, and Erin Averett for permission to use models from the Athienou Archaeological Project in this project. Thanks are also due to Robert Cook and Marcus Schulenburg for the use of the Guard site excavation trench models. We would also like to acknowledge Marquette's Department of Social and Cultural Sciences for support of this collaboration in teaching the introductory class. 


\section{REFERENCES}

Robert A. Cook, Aaron R. Comstock, Kristie R. Martin, Jarrod Burks, Wendy Church, and Melissa French. 2015. Early Fort Ancient Village Life in Southeast Indiana: The Guard Site Example. Southeastern Archaeology34, (2015), 95-115. DOI: 10.1179/2168472314Y.0000000007

Derek B. Counts, Erin W. Averett, Kevin Garstki, and Michael K. Toumazou. Forthcoming. Visualizing Votive Practice: Exploring Limestone and Terracotta Sculpture from AthienouMalloura through 3D Models. ASOR and The Digital Press at the University of North Dakota.

Derek B. Counts 1998. Contributions to the Study of Cypriote Sculpture: Limestone Votives from Athienou-Malloura. Ph.D. Dissertation. Brown University, Providence, RI. UMI Order Number: 9830427

Derek B. Counts, Erin Walcek Averett, and Kevin Garstki. 2016. A fragmented past: (re)constructing antiquity through 3D artefact modelling and customised structured light scanning at AthienouMalloura, Cyprus. Antiquity90, 349 (February 2016), 206-218. DOI: 10.15184/aqy.2015.181

Carolina Cruz-Neira, Daniel J. Sandin, Thomas A. DeFanti, Robert V. Kenyon, and John C. Hart. 1992. The CAVE: audio visual experience automatic virtual environment. Communications of the ACM 35, 6, 64-73. DOI: $10.1145 / 129888.129892$

R.P. Stephen Davis, Patrick C. Livingood, H. Trawick Ward, and Vincas P. Steponaitis. 1998. Excavating Occaneechi Town. Archaeology of an Eighteenth-Century Indian Village in North Carolina. University of North Carolina Press, Chapel Hill (CD-ROM).

Nicolò Dell'Unto. 2018. 3D Models and Knowledge Production. In Isto Huvila, eds. Archaeology and Archaeological Information in the Digital Society. London: Routledge, 54-69.

Harold L. Dibble, Shannon P. McPherron, and Barbara J. Roth. 2000. Virtual Dig: A simulated archaeological excavation of a Middle Paleolithic site in France. Mountain View, California: Mayfield Pub. Co.

Paola Di Guiseppantonio Di Franco, Fabrizio Galeazzi, and Carlo Camporesi. 2012. 3D Virtual Dig: a 3D Application for Teaching Fieldwork in Archaeology', Internet Archaeology32. DOI: $10.11141 /$ ia.32.4

Claudia A. Engel, 2017. 3D models in Anthropology, Stanford Digital Library Blog. Retrieved May 24, 2019 from https://library.stanford.edu/blogs/digital-library-blog/2017/04/3d-modelsanthropology

Kate Ellenberger. 2017. Virtual and Augmented Reality in Public Archaeology Teaching. Advances in Archaeological Practices 5, 3, 305-309.

Maurizio Forte. 2014. 3D Archaeology: New Perspectives and Challenges- The Example of Çatalhöyük. Journal of Eastern Mediterranean Archaeology and Heritage Studies, 2, 1, 1-29.

Fabrizio Galeazzi, Paola Di Giuseppantonio Di Franco, and Nicolò Dell'Unto. 2010. 3D Cybermaps of Western Han mural tombs. In Maurizio Forte, ed. Cyber-Archaeology. British Archaeological Reports International Series 2177. Oxford: Archaeopress, 97-108.

Fabrizio Galeazzi and Paola Di Giuseppantonio Di Franco. 2017. Theorising 3D Visualisation Systems in Archaeology: Towards more effective design, evaluations and life cycles. Internet Archaeology 44. DOI: 10.11141/ia.44.5

Kevin Garstki, Marcus Schulenburg, and Robert A. Cook. 2018. Practical Application of Digital Photogrammetry for Fieldwork in the American Midwest: An Example from the Middle Ohio Valley. Midcontinental Journal of Archaeology 43, 2 (May 2018), 133-150. 
DOI: $10.1080 / 01461109.2018 .1452364$

Kevin Garstki. 2018. Virtual Authority and the Expanding Role of 3D Digital Artefacts. In Paola. Di Giuseppantonio Di Franco, Fabrizio Galeazzi, and Valentina Vassallo, eds Authenticity and Cultural Heritage in the Age of $3 D$ Digital Reproductions. Cambridge: Cambridge University Press, 75-81.

Matthew D. Howland. 2017. 3D Recording in the Field: Style Without Substance? In Thomas E. Levy and Ian W.N. Jones, eds. Cyber-Archaeology and Grand Narratives: Digital Technology and DeepTime Perspectives on Culture Change in the Middle East. Springer, 19-33.

Kyle A. Knabb, Jurgen P. Schulze, Falko Kuester, Thomas A. DeFanti, and Thomas E. Levy. 2014. Scientific Visualization, 3D Immersive Virtual Reality Environments, and Archaeology in Jordan and the Near East. Near Eastern Archaeology, 77, 3, 228-232.

Thomas E. Levy, Vid Petrovic, Thomas Wypych, Aaron Gidding, Kyle Knabb, David Hernandez, Neil G. Smith, Jürgen P. Schlulz, Stephen H. Savage, Falko Kuester, Erez Ben-Yosef, Connor Buitenhuys, Casey Jane Barrett, Mohammad Najjar, and Thomas DeFanti. 2010. On-site digital archaeology 3.0 and Cyber-archaeology: into the future of the past - new developments, delivery and the creation of a data avalanche. In Maurizio Forte, ed. Cyber-Archaeology. British Archaeological Reports International Series 2177. Oxford: Archaeopress, 135-53.

T. Douglas Price and Anne Birgette Gebauer. 1997. Adventures in Fugawiland: A Computer Simulation in Archaeology(Second Edition). Mountain View, California: Mayfield Pub. Co.

Paul Reilly. 1992. Three-dimensional modelling and primary archaeological data. In Paul Reilly and Sebastian Rahtz, eds. Archaeology and the Information Age: A Global Perspective. Routledge, 147-176.

Christopher H. Roosevelt, Peter Cobb, Emanuel Moss, Brandon R. Olson, and Sinan Ünlüsoy. 2015. Excavation is Destruction Digitization: Advances in Archaeological Practice. Journal of Field Archaeology 40, 3 (June 2015), 325-346. DOI: 10.1179/2042458215Y.0000000004

Michael K. Toumazou, Derek B. Counts, Erin W. Averett, Jody M. Gordon, and P. Nick Kardulias. 2015. Shedding light on the Cypriot rural landscape: investigations of the Athienou Archaeological Project in the Malloura Valley, Cyprus, 2011-2013. Journal of Field Archaeology 40, 204-220. DOI: 10.1179/0093469015Z.000000000112

Michael K. Toumazou and Derek B. Counts. 2011. Excavation at Malloura (1990-2010): Context, Methods, and Results. In Michael K. Toumazou, P. Nick Kardulias, and Derek B. Counts, eds. Crossroads and Boundaries: The Archaeology of Past and Present in the Malloura Valley, Cyprus. Annual of the American Schools of Oriental Research 65. Boston, MA: American Schools of Oriental Research, 67-86.

Received July 2018; revised November 2018; accepted January 2019 